\title{
Where You Stand Is What You See: We See a Need for More Primary Care Research Funding
}

\author{
John M. Westfall, MD, MPH
}

National Institutes of Health (NIH) research funding allocations are out. Family Medicine has been successful. Between 2002 and 2006, departments of family medicine received only $0.20 \%$ of all NIH grant dollars-just 170 grants, for a total of $\$ 57$ million. However, just a decade later, between 2011 and 2014, family medicine funding climbed to $0.22 \%$ of the NIH budget: 192 grants worth $\$ 71$ million-an increase of two hundredths of $1 \%$ in just a decade. From an NIH perspective, at least, family medicine advocacy efforts have paid off.

What about from a Family Medicine perspective? Cameron et $\mathrm{al}^{1,2}$ report a disturbing lack of trend in family medicine NIH funding over the past 10 years. There has been very little change in family medicine research funding. Family medicine $\mathrm{NIH}$ applications are still $25 \%$ less likely to be funded than all other applicants. We've been through this before. In 1960 White et $\mathrm{al}^{3}$ made famous an image of where our patients live their lives, where they seek their care, and where the nation funds the research: people live in communities and get their health care from primary care practices, but research is funded in academic tertiary and quaternary care hospitals, or at least $99.78 \%$ of the money goes there. So, perhaps from

From the Department of Family Medicine, Eugene S. Farley Jr. Health Policy Center, University of Colorado School of Medicine, Denver; and the North American Primary Care Research Group Research Advocacy Committee, Leawood, KS.

Funding: none.

Conflict of interest: none declared.

Corresponding author: John M. Westfall, MD, MPH, Department of Family Medicine, Eugene S. Farley Jr. Health Policy Center, University of Colorado School of Medicine, PO Box 6508, Aurora, CO 80045 (E-mail: jack.westfall@ ucdenver.edu).

\section{See Related Articles on Pages} 528 and 531. a family medicine vantage point, we have not been

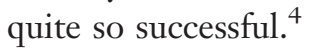

Where you stand is what you see. And the NIH stands in basic science, rats and zebrafish, single organs, individual disease research. It simply cannot see the primary care angle in the research world. Most readers of the $7 A B F M$ stand in the primary care world and see the following, informed by and derived from the North American Primary Care Research Group website ${ }^{5}$ :

- The majority of health care takes place in primary care practices.

- The overall health of a population is directly linked to the strength of its primary health care system. A strong primary care system delivers higher quality of care and better health for less cost.

- Primary care provides a "medical home" and considers the whole person, as they exist in family, community, and population, including multiple illnesses, preventive care, health promotion, and the integration of mind and body.

- Primary care is:

- Complex and comprehensive

- Where most people first bring their symptoms and health concerns and have their first touch with the health care system

- Where people develop healing, trusting relationships with their physician and other primary care providers

- Primary care research includes:

- Translating science into the practice of medicine and caring for patients

- Understanding how to better organize health care to meet patient and population needs

- Evaluating innovations to provide the best health care to patients

- Engaging patients, communities, and practices to improve health 
However, very little is known about important topics such as how primary care services are best organized, how to maximize and prioritize care, best practices for managing complex multimorbidities, how to introduce and disseminate new discoveries so they work in real life, and how patients can best decide when and where to seek care. The delivery of primary care is not just a compilation of individual disease specialty care. And primary care research is not just a mix-tape of the latest top-40 specialty research hits.

It is time for primary care to claim its rightful position at America's medical and health care science leadership table. Our discipline has grown up, and our research infrastructure is poised to produce relevant and rigorous results. ${ }^{6,7}$ It is time to sit at the grown-ups' table. It would be nice to be invited to that table, but we may need to elbow our way in or get there early, before the rest of them sit down, or add a folding chair from the closet. Either way, sit there we must.

It is time for an Institute of Primary Care Research at the NIH to study the core basic components of comprehensive primary care.

It is time to billionize the Agency for Healthcare Research \& Quality (AHRQ) and direct it to apply those resources to find the best way to offer primary care services to have the greatest impact on our nation's health.

It is just about time to reauthorize the PatientCentered Outcomes Research Institute (PCORI), and it is absolutely time for PCORI to invest its resources in the comparative effectiveness of managing the complexities of primary care patients.

In the meantime, it is also crucial to show the $\mathrm{NIH}$ and PCORI what they are missing. If you stand in an academic specialty practice, what you see is specialty care: single organ, individual disease, selected nonrepresentative patients, only the newest drugs and devices. Physicians completing a residency at a university hospital may never see thrombolytics given for a heart attack because those patients go to the catheterization laboratory. Yet every rural doctor must know when and how to deliver intravenous thrombolytic medication. We wonder why the newest discoveries take decades to leak out to primary care; it is because primary care was typically not involved in the discovery. The research is just not relevant to the patients in primary care practices, where those patients receive the majority of their care. Primary care providers, researchers, and patients offer the best opportunity to make NIH/AHRQ/PCORI research meaningful and ready for rapid implementation and dissemination. In 2016 it is unacceptable to have a clinical research review panel that does not include several primary care providers, researchers, and patients. Family medicine researchers should be on the PCORI board of governors and active on the PCORI methodology committee.

In the meantime, it is up to primary care researchers to write the best grants, focus our research on meaningful outcomes, hone our methods and methodologists. We must be ready to perform at the highest level, to deserve our spot at the grown-ups' table. We must identify the research that matters to our patients, deliver great grant proposals, conduct outstanding research, disseminate the hell out of it, and be ready to step onto a review panel or study section and provide thoughtful, rigorous grant reviews.

In the meantime, it is essential for departments of family medicine to leverage other resources for their primary care research efforts: the Health Resources and Services Administration, local and national foundations, clinical income, and local university and academic medical center resources.

It is crucial for Family Medicine and other primary care leaders to be bold. Our few researchers on NIH study sections and review panels must act with passion and quality, boldly bring the primary care perspective to the review process, and nominate their colleagues to join them as reviewers. Our department chairs must use the bully pulpit of their position to declare the value of primary care research and request—nay, demand-attention and resources, both local and national. Our prominent Institute of Medicine members must preach boldly the need for primary care research, using every connection and network node they have to move this agenda forward. It is incumbent on primary care researchers and providers to obtain leadership positions at the NIH, AHRQ, and PCORI, and then behave like primary care researchers.

The United States spends billions of dollars each year on medical research; the NIH alone spends $\$ 33$ billion on biomedical research-that's 33 billion taxpayer dollars. It is time to focus a larger portion of this money on the place where most of the people get most of their care most of the time. It is time for the American people to get a better return on their investment. Primary care research 
can provide that benefit. And our nation will be healthier for it.

Family Medicine needs you. Apply to be on an NIH study section. Write a letter to your senator or representative about the need for primary care research. Stop by the NIH/AHRQ/PCORI and meet a project officer or two. Come to our primary care research advocacy breakfast table at the North American Primary Care Research Group annual meeting this November to learn more and get involved. ${ }^{8}$

To see this article online, please go to: http://jabfm.org/content/ 29/5/525.full.

\section{References}

1. Cameron BJ, Bazemore AW, Morley CP. Lost in translation: NIH funding for family medicine research remains limited. J Am Board Fam Med 2016;29:528-30.

2. Cameron BJ, Bazemore AW, Morley CP. Federal research funding for family medicine: highly con- centrated, with decreasing new investigator awards. J Am Board Fam Med 2016;29:531-2.

3. White KL, Williams TF, Greenberg BG. The ecology of medical care. N Engl J Med 1961;265:885-92.

4. Mazur S, Bazemore A, Merenstein D. Characteristics of early recipients of Patient-Centered Outcomes Research Institute funding. Acad Med 2016; 91:491-6.

5. North American Primary Care Research Group. Key messages for primary care research. Available from: http://www.napcrg.org/Portals/51/Documents/ Key_messages_for_PC_research_FINAL.pdf. Accessed May 26, 2016.

6. Pimlott N, Katz A. Ecology of family physicians' research engagement. Can Fam Physician 2016;62: 385-90.

7. deGruy FV, Ewigman B, DeVoe JE, et al. A plan for useful and timely family medicine and primary care research. Fam Med 2015;47:636-42.

8. North American Primary Care Research Group. About us. Research Advocacy Committee. Available from: http://www.napcrg.org/AboutUs/Committees/ ResearchAdvocacy. Accessed June 30, 2016. 